Supplement of SOIL, 8, 113-131, 2022

https://doi.org/10.5194/soil-8-113-2022-supplement

(c) Author(s) 2022. CC BY 4.0 License.

(c) (1)

Supplement of

\title{
Content of soil organic carbon and labile fractions depend on local com- binations of mineral-phase characteristics
}

\section{Malte Ortner et al.}

Correspondence to: Malte Ortner (ortner@uni-trier.de) and Sören Thiele-Bruhn (thiele@uni-trier.de)

The copyright of individual parts of the supplement might differ from the article licence. 


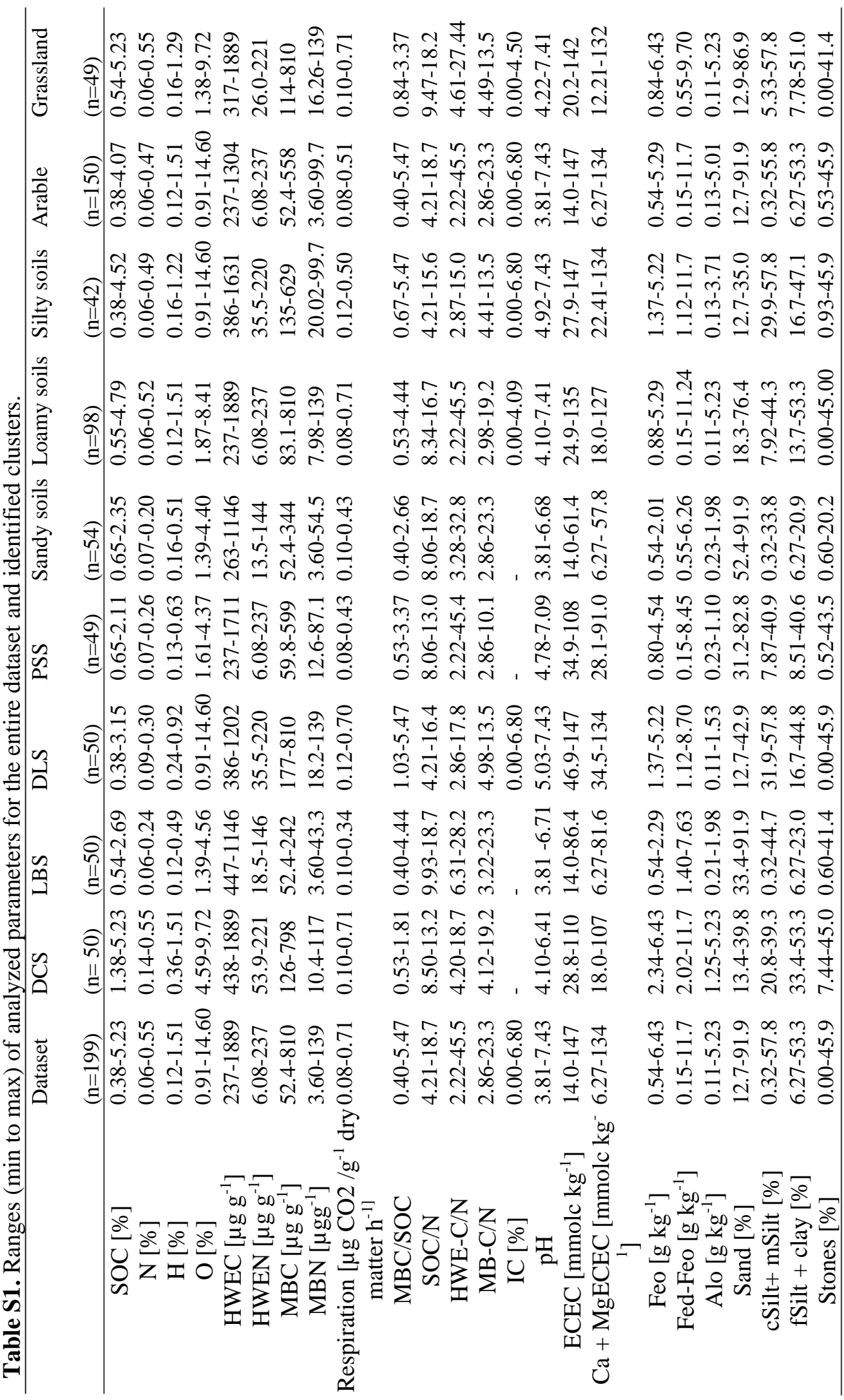




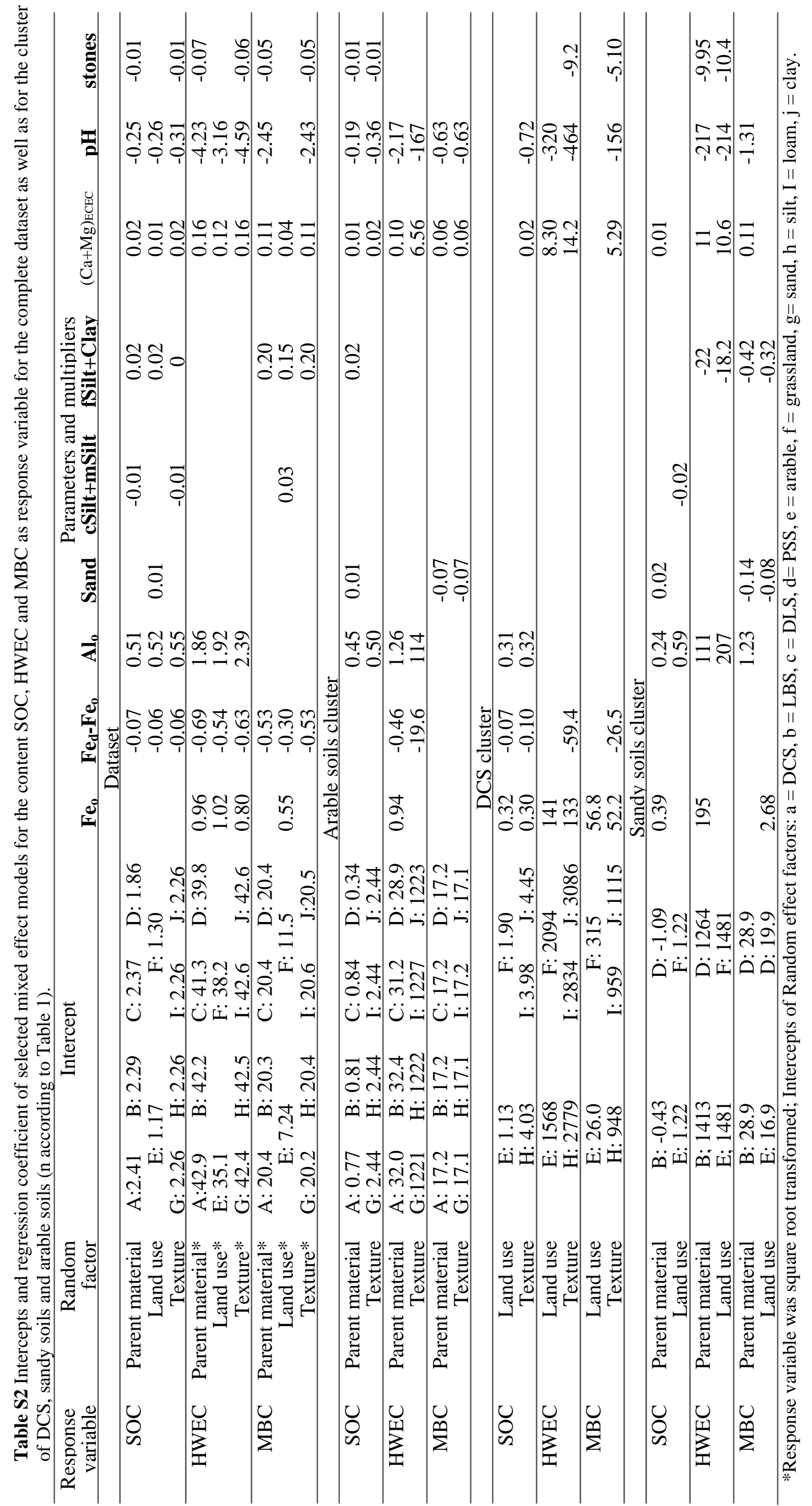




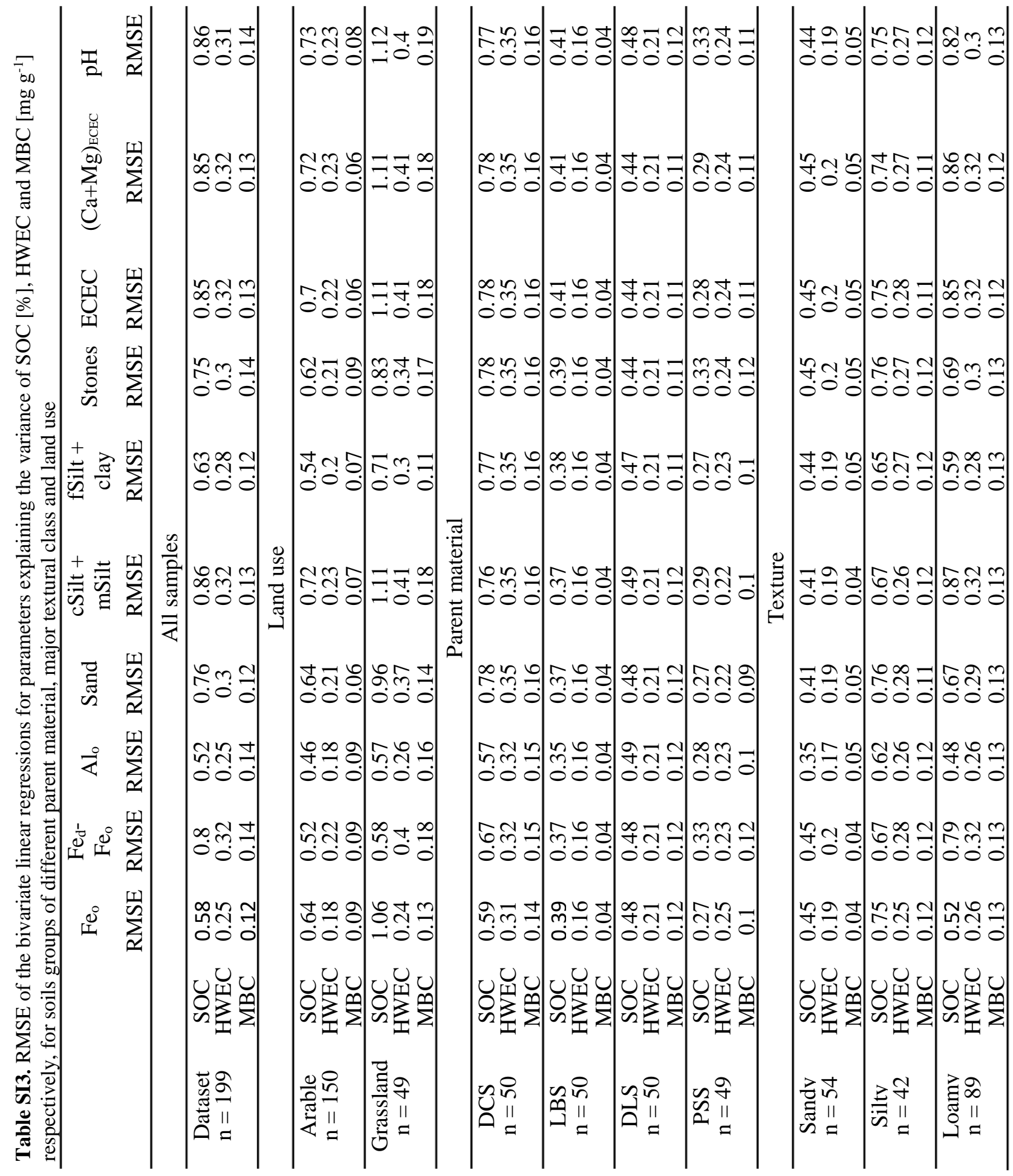


Table S4. $\mathrm{R}^{2}$ and RMSE [ $\mathrm{mg} \mathrm{g}^{-1}$ ] for implementation of the global dataset to local clusters for HWEC and MBC.

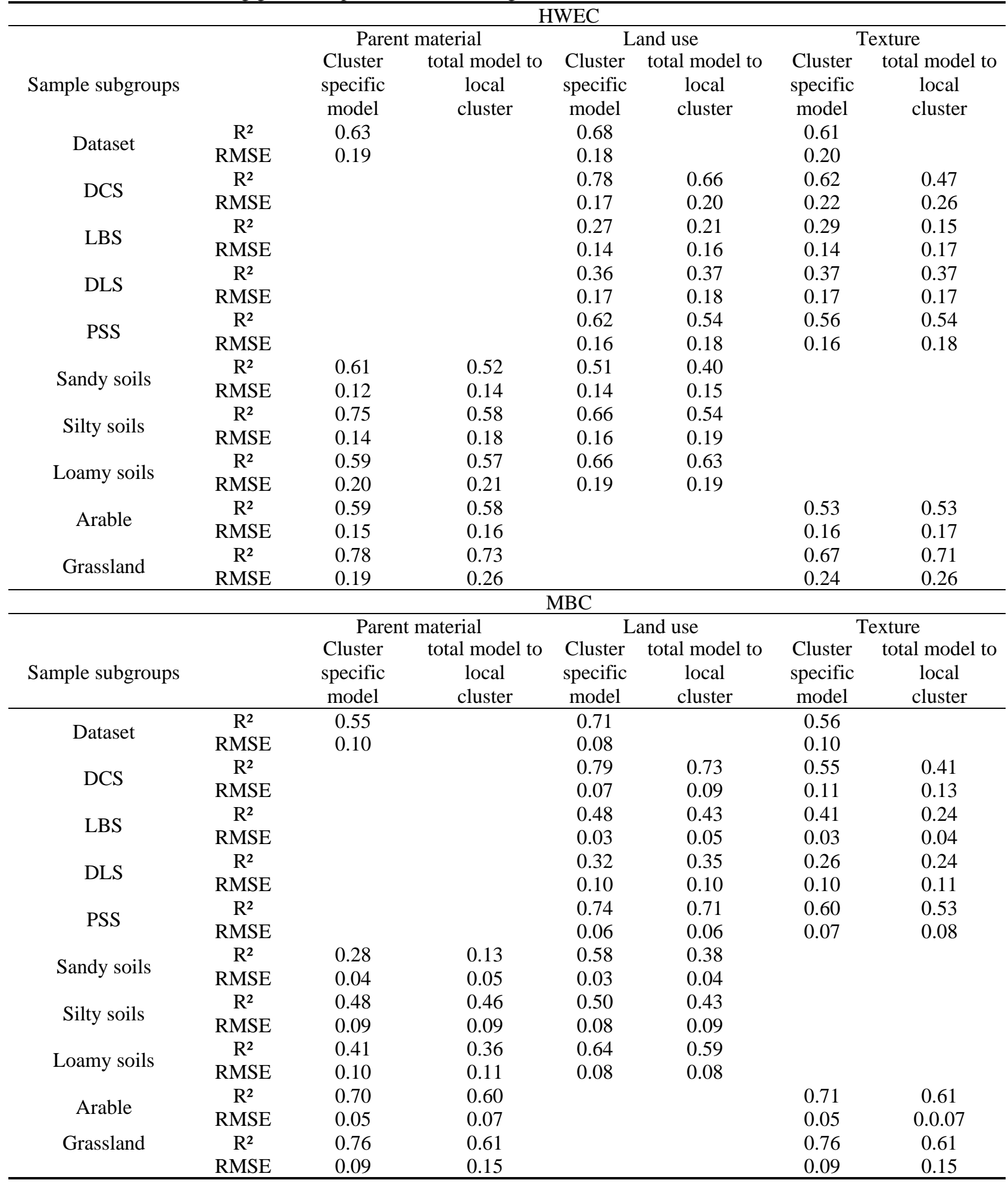


Figure S1. Clustering of the dataset according to land use along the first two principal components.

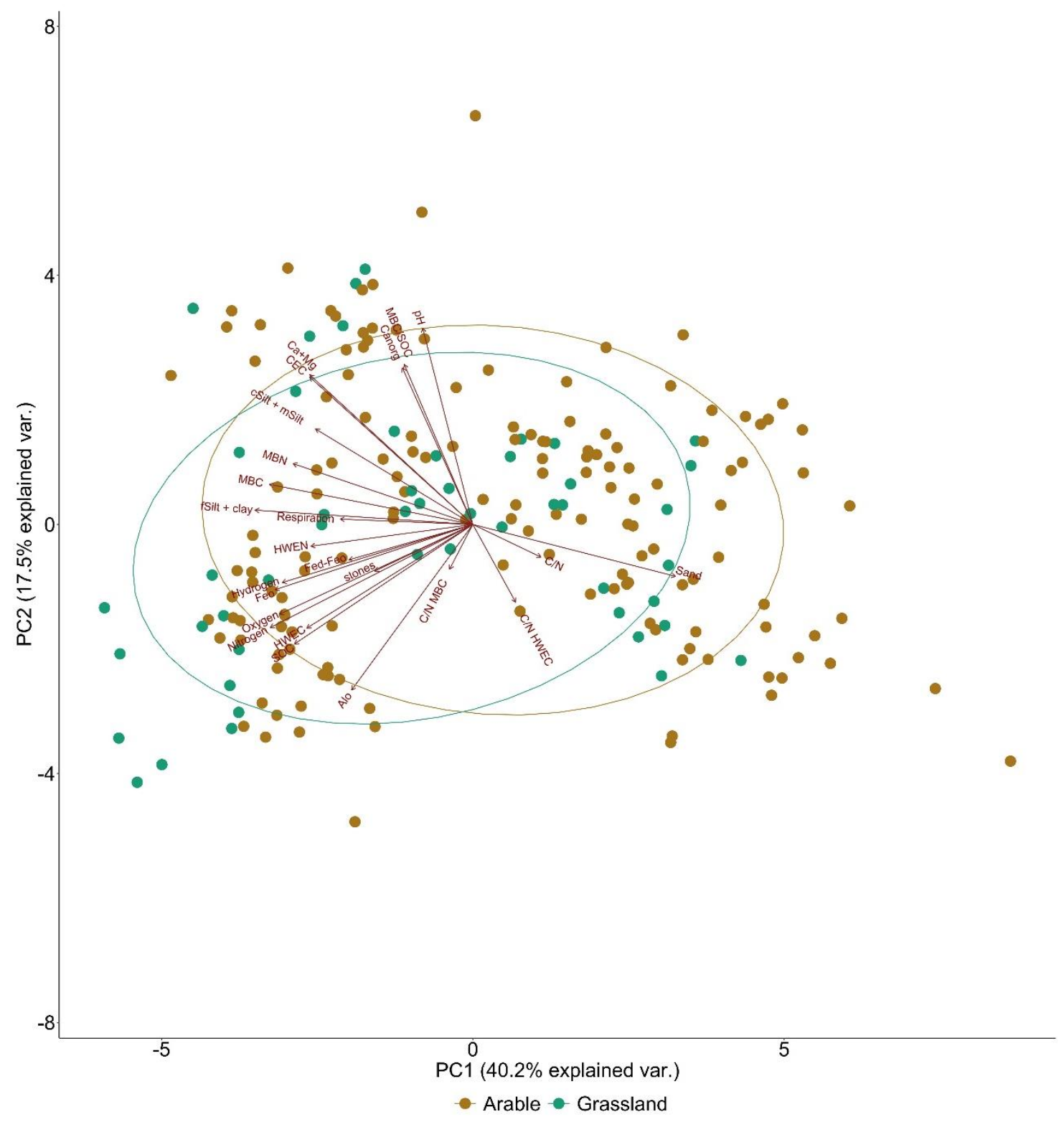

